\title{
AS REFORMAS AGRÁRIAS NO PROCESSO DE DESENVOLVIMENTO *
}

José Francisco da Silva

\section{INTRODUÇĀO:}

A ideologia do desenvolvimento surgiu na década de sessenta, tendo origem nos organismos internacionais vinculados às Naçōes Unidas, a partir da constatação de que o mundo encontrava-se dividido em dois tipos de paises: de um lado os paises desenvolvidos, ou paises ricos, e do outro lado os paises subdesenvolvidos, ou países pobres, representados pela quase totalidade das naçōes da América Latina, África e Ásia. Essa classificação era basea$\mathrm{da}$ em indicadores relativos às condiçōes econômicas e sociais existentes em cada um dos paises e refletia a intenção dos organismos internacionais em que fossem promovidos esforcos para "tirar" os paises pobres do scu subdesenvolvimento. Assim, o desenvolvimento era concebido como a melhoria das condiçōes econômicas, sociais, culturais e até mesmo politicas dos paises pobres. A melhoria das condiçōes econōmicas seria representada pelo crescimento da economia destes paises, ao mesmo tempo que por uma melhor distribuiçăo de renda gerada pelo crescimento econômico, resultando em melhoria das condiçōes habitacionais, sanitárias, educacionais e até mesmo de participação política das populaçōes nos países pobres.

Como um dos fatores identificados como responsáveis pelo subdesenvolvimento era o atraso que se verificava na agricultura desses países, foram feitas propostas no sentido de modernizar a agricultura dos países pobres e, entre elas, figurava com destacada importância a proposta de Reforma Agrária.

Sem dúvida, o Brasil sofreu a influência dessa ideologia e seus efeitos fizeram-se sentir, através da assessoria e dos financiamentos das agências in. ternacionais ao nosso Governo.

* Trabalho apresentado no semindrio "Agricultura e Desenvolvimento", realizado de 13 a 16 de outubro de 1981 em Campina Grande, promovido pelo Mestrado em Economia (Rurall da Universidade Federal de Paraba - Campus II ISub. trtulos da Redacäol.

* Presidente da Confederacäo Nacional dos Trabalhadores na Agricultura (CONTAG).

\begin{tabular}{|l|l|l|l|l|l|}
\hline Rev. RAIZES & Campina Grande & Ano I & $N^{0}$, & pgi. $135-146$ & jul. - dez./ 1982 \\
\hline
\end{tabular}


Entretanto, a política de desenvolvimento adotada por nosso país, através dos vários governos que se vêm sucedendo nos últimos 17 anos, nāo permitiu que viesse a ocorrer um real desenvolvimento, entendido como a melhoria das condiçōes de vida da maioria da população brasileira.

Não podemos negar que ocorreu um processo de crescimento econōmico, sobretudo mediante a intensificação da industrializaçāo do pais e a modernização do processo produtivo na agricultura, particularmente na Regiāo Centro-Sul. Entretanto, as condições sociais da maioria da população, principalmente da população rural, vêm piorando a cada ano; haja visto o desemprego, o sub-emprego, a multiplicaçāo do "boia-fria", o êxodo rural, o favelamento nas cidades.

A razão principal destes fenômenos reside no fato de não ter sido realizada a Reforma Agrária no Brasil, mas ao contrário, o que vem ocorrendo na agricultura é um processo que podemos chamar de anti-Reforma Agrária. As consideraçôes que seguem parecem confirmar esta afirmação.

\section{O PROCESSO DE ANTI-REFORMA AGRĀRIA}

A concentraçāo da propriedade da terra no Brasil agravou-se substancialmente nos últimos anos, reduzindo drásticamente as "terras de trabalho" e as oportunidades de sobrevivência dos trabalhadores rurais e suas famflias. Os dados preliminares do Recadastramento do INCRA de 1978 revelam que o número das pequenas propriedades continua se reduzindo, enquanto o número de grandes propriedades, especialmente aquelas com mais de 100 mil hectares, se multiplica cada vez mais rapidamente, passando de 62 imóveis em 1967, e 83 em 1972, para 141 imóveis cadastrados em 1978.

As propriedades com menos de 10 hectares, que representavam $36 \%$ dos imóveis em 1967 ocupando quase $2 \%$ da área cadastrada, foram reduzidas para $28 \%$ do total de imóveis passando a ocupar apenas $1 \%$ da área. Enquanto isso, as propriedades de 10 mil hectares a mais, que representavam $0,1 \%$ dos imóveis com 16\% da área cadastrada, passaram a controlar em 1978, $25 \%$ de nossas terras.

O Nordeste, região onde desde o início de nossa colonização, a terra e a renda estiveram concentradas em poucas mãos, não fugiu a essa tendêncja geral. Se os dados do cadastramento de 1972 já mostravam que os latifúndios, representando menos de $20 \%$ dos imóveis, controlavam mais de 80\% da área, a comparação dos dados de 1972 com os de 1978 revelam que 
o crescimento da área média do imóvel rural no Nordeste foi superíor até mesmo ao da Regiāo Centro-Oeste, só sendo superado pela Região Norte. Entre 1967 e 1972, as propriedades com mais de 10.000 ha. expandiram sua participação, nas terras cadastradas, em cerca de 8,2 milhões de hectares.

E importante notar que esse quadro agravou-se, apesar dos inúmeros progrumas governamentais para a região, todos eles, supostamente, com objetivos sociais. O PROÁLCOOL expande-se em áreas até agora exploradas por posseiros, parceiros e arrendatários, com o cultivo de alimentos. Reduz a oferta de terras para a pequena agricultura e, consequentemente o nivel de emprego. Transforma parte dos trabalhadores em assalariados, percebendo rendimentos menores do que auferiam quando trabalhavam em suas próprias plantações e, na maioria dos casos, sem se beneficiarem das garantias da Legislação Traballista.

O plantio de pastagens artificiais para a criação de gado no sertão nordestino, já há muitos anos que vem sendo estimulado pelo Governo. Basta ver que, analisando-se os projetos agropecuários e agroindustriais do Fundo de Investimento do Nordeste - FINOR - entre 1965 e 1976, praticamente $50 \%$ das áreas dos projetos estão cobertas com pastagem artificial contra menos de $8 \%$ com culturas agrícolas. Quando se tomam as atividades dos projetos, os dados são ainda mais gritantes: praticamente $65 \%$ das atividades dos projetos aprovados sāo pecuários, contra menos de $5 \%$ de ativida. des agricolas. Acabando com o tradicional sistema agrícola "gado-algodāo", que permitia ao trabalhador, com toda a opressão, plantar milho e feijão para sua subsistència, o resultado dos programas governamentais tem sido expulsar o trabalhador da terra, fazer desaparecer terra para arrendamento e diminuir a produção de produtos para a alimentação.

A política de construção de barragens para a produçāo de energia elétrica não tem sido menos nociva aos trabalhadores das áreas em que seus projetos são implantados. Quando não são obrigados a deixarem as terras onde sempre viveram e trabalharam, perdem as condiçōes de continuarem com sua tradicional agricultura de vazante. As indenizaçōes que lhes têm sido pagas são irrisórias.

O mesmo se pode dizer da política de irrigação. Os trabalhadores deslocados, com os projetos da CODEVASF e do DNOCS, não são convenientemente indenizados. Os critérios de seleção de irrigantes excluem esses trabalhadores que deveriam ser seus principais beneficiários. E, sobretudo, es- 
ses projetos assentam muito menos trabalhadores do que expulsam. Ao invés de criadores de emprego, são, portanto, destruidores de emprego.

Note-se que, de alguns anos para cá, a própria política para a área vem privilegiando a instalação de agroindústrias em prejuizo ao assentamento de colonos, nos perimetros irrigados, o que reforça a tendência geral à concentraçāo da terra e da renda.

Essa superconcentração da terra, aliada a toda uma política de favorecimento à grande propriedade, que vai desde os incentivos fiscais até o financiamento à expansão das pastagens e da cultura de cana-de-açúcar para a produção do álcool, é, pois, a grande responsável pela marginalização dos trabalhadores rurais, pela multiplicação das áreas te tensão social, que se generalizam em todo o Pais, enfim, pelas lutas cotidianas por um pedaço de terra.

Outro fator que contribui decisivamente para o crescimentu dos conflitos de terra é a grilagem que, em toda a Região Nordeste, acompanha de perto as obras de infra-estrutura que vão sendo implantadas pelos programas oficiais do Governo. A cada construção de barragem, a cada abertura de uma nova estrada, os grileiros vão se apossando das terras dos antigos moradores, com o intuito de especular sobre essas terras, valorizadas no mercado.

Em todo o Nordeste e particularmente no Estado da Bahia, a grilagem de terras se tornou um ato rotineiro de violência contra os trabalhadores e suas familias. Essa grilagem cresce favorecida pelos incentivos do Governo e das empresas governamentais que atuam na Região. No Vale do São Francisco, que abrange quatro Estados dessa Região, a grilagem desenvolve-sé com a mesma rapidez que os projetos da CHESF e CODEVASF, mais preocupados cum a instalação de grandes projetos agropecuários e agroindustriais, de resultados econômicos a curto prazo, do que com a melhoria das condições de vida dos trabalhadores, apenas considerados como mão-de-obra barata para as grandes empresas monocultoras implantadas na Região.

\section{A VIOLENCIA DA ANTI-REFORMA}

Os conflitos de terra se alastram por todo o Nordeste, reproduzindo em menor escala, uma situação de violência que é vivida no meio rural de todo o País. 
Durante o ano de 1980, a CONTAG denunciou às autoridades do País, graves casos de conflitos de terra em 15 Estados do Brasil e no Território Federal de Rondônia, os quais totalizaram 96 casos de conflitos pela posse da terra. Ao todo, 20.678 familias de camponeses estiveram diretamente envolvidas nesses conflitos, o que soma mais de 103 mil pessoas lutando pela terra em que vivem e trabalham.

Só no Estado da Pararba foram denunciados 10 casos de tensão social: Fazenda Camucim e Fazenda Sede Velha de Abiai, no munićpio de Pitimbu; Alagamar, Piacas, Maria de Melo, Urna, Salomão, Fazenda Nova e Riacho dos Currais, que fazem parte da Grande Alagarnar, nos municipios de Itabaiana e Salgado de São Félix, Mucatu, município de Alhandra; Fazenda Sapucaia, Carvalho, Porteira e Capivara, município de Bananeiras e Solânea; Quandu em Barra de Santa Rosa; Cachorrinho e Coqueirinho, município de Pedras de Fogo e Fazenda Sítio, no município de Dona Inès. Todos esses conflitos de terra, que envolvem centenas de familias de trabalhadores rurais, decorrem fundamentalmente da expansão da cultura de cana-de-açúcar para a produção de álcool em áreas tradicionalmente produtoras de alimentos paía o mercado local e regional e de grande concentraçāo de camponeses. A importância dessa produção para a Região Nordeste foi reconhecida pelo Governo Federal, tanto, que declarou essa área prioritária para a Reforma Agrária.

No Estado da Bahia, recentemente, o Movimento Sindical de Trabalhadores Rurais encaminhou às autoridades amplo relatório sobre a gravidade da situação em que se encontram 12 municípios do Estado, vitimas de um processo violento de grilagem, acobertado por autoridades locais. Os municípios de Mucuri, Marcionnlio Souza, Boa Vista do Tupim e Iaçu foram considerados áreas críticas, naquele "dossier". Em Mucuri, o Juiz de Direito da Comarca de Caravelas usou um verdadeiro aparato policial, para fazer cumprir uma ordem de despejo contra 60 familias de posseiros, apesar dessa ordem ter sido sustada pelo Tribunal de Justiça da Bahia, acatando mandado de segurança em favor dos trabalhadores. Um total de 36 chefes de familia foram presos por resistirem à ordem de despejo. Em Marcionilio Souza, Boa Vista do Tupim e Iaçu, todos na microrregião de Itaberaba, as violências contra os posseiros foram comandadas pelo Tenente Barbosa, da Polícia Militar, que se coloca a serviço da famnlia Medrado, grande latifundiária na Região. As pressões foram de toda ordem: intimações, prisōes coletivas, espancamentos de centeras de famnias, etc. Por diversas vezes, a FETAG-BA denunciou essses casos à Sectetaria de Segurança Pública e a outras autorida- 
des estaduais. No caso de Iaçu, o Governo Federal desapropriou a área em litigio. São mais de 2 mil familias ameaçadas nesses 3 municípios.

Em Sergipe, a situação não é diferente dos demais Estados nordestinos. Assim, 70 familias de trabalhadores rurais, moradoras da Fazenda Santana dos Frades, município de Pacatuba, há mais de uma geração, sofreram inúmeras violências para abandonar a sua terra. A pretexto de notificar os trabalhadores da sentença que negara liminar em ação de manutenção de posse, dois Oficiais de Justiça compareceram ao Povoado acompanhados de dois Delegados de Polícia, dois soldados e majs investigadores de Aracaju, fortemente armados com fuzis, rifles, metralhadoras e revólveres, cometendo uma série de arbitrariedades contra as famnlias de traballhadores rurais. Os trabalhadores, para garantirem a sua sobrevivência e como estāo impedidos de plantar, colheram cerca de 90 mil cocos, beifeitorias suas, que tiveram dificuldades de vender, boicotados pela empresa SERAGRO - Serigy Agroindustrial Lida., grande industrializadora da regiāo e proprietária da área em questão. En agosto de 1980. a juiza da comarca de Pacatuba expediu manda. dos de prisão preventiva contra posseiros e contra o presidente do sindicato, acusado de crime por estar defendendo os associados. Os trabalhadores e o presidente do sindicato permaneceran presos por um mês, apesar das denúncias às autoridades e da mobilização para a libertação dos presos em todo o País, feita através do Movimento Sindical, Igreja, Partidos Políticos de oposição e por entidades civis que apoiam a luta dos trabalhadores.

Pernambuco, por sua vez tem sido palco de inúmeras violências pela posse da terra. Em Igarassu e Paulista centenas de famnlias de trabalhadores rurais, inclusive crianças, dos engenhos Santa Cruz, Pirajui, Mulata, Novo e Caiana, foram vítimas de violências cometidas por supostos proprietários, além de sofrerem a destruição de casas e benfeitorias. expulsão de posseiros, etc. Em 1980, o trabalhador rural Jaime Barbosa dos Santos, líder dos trabalhadores. no município de Santa Maria da Boa Vista, foi assassinado, em decorrência de sua luta contra grileiros da região. Umas 700 famnlias de traba. thadores rurais moradores dos imóveis Fragoso e Ouro Preto, em Paulista, foram ameaçadas de expulsāo através de ameaças, destruiçāo de benfeitorias, e 41 familias de trabalhadores rurais da Fazenda Tabu Surubim, foram ameaçadas de expulsão da área que cultivam há muitos anos, através de um mandado de despejo judicial. O Movimento Sindical reivindicou a desapropriação dessa área por interesse social. 
No Ceará, onde predominam o arrendamento e a parceria, inúmeras têm sido as lutas dos trabalhadores pelo cumprimento das disposições do Estatuto da Terra, no que diz respeito ao valor do arrendamento e o quantum da partilha da produção agrícola. Em Quixadá, os trabalhadores da Fazenda Monte Castelo vêm depositando o foro na justiça e, consequentemente, vêm também sofrendo as arneaças e perseguiçōes do proprietário de terras. Trabalhadores da Comunidade Sítio Faveira, Carnaubal, foram obrigados ao pagamento exagerado do arrendamento e sujeitos a violências fŕsicas pelo proprietário, auxiliado por pistoleiros, policiais e pelo juiz local. Muitas vezes, ainda, os grandes proprietários cometem inúmeras violências no sentido de expulsar os antigos moradores de suas terras, tendo $\epsilon_{m}$ vista a expansäo das pastagens. Em Parambu, Paraiba, 150 familias de arrendatários, moradoras há anos nos sítios Ingá e Fagundes, sofreram todo tipo de ameaça e opressão para abandonarem suas posses. Algumas familias foram expulsas de suas terras e outras foram proibidas, pelo latifundiário, de executar qualquer tipo de plantio. Em 1980 essa área foi desapropriada por interesse social.

No Rio Grande do Norte, os trabalhadores rurais do Vale do Açu estão ameaçados pela construçao de uma barragem, face à incerteza do reassentamento e dos critérios de seleção no Projeto de Colonização. Em "Baixa da Preguiça", município de Touros, 37 familias estāo ameaçadas de expulsão pelo grupo proprietário da Fazenda Ranho. Em São Bento do Norte, 12 familias foram expulsas violentamente pela Empresa Refloricultura S/A.. para implantar, com incentivos oficiais um projeto de reflorestamento. Tudo isto só para citar alguns exemplos de conflitos neste Estado.

Contra esta situação luta o Movimento Sindical de Trabalhadores Rurais, sob a coordenação da CONTAG e das Federações Estaduais. Mesmo nas conjunturas mais adversas essa luta não foi interrompida.

A defesa firme dos interesses da Classe tem feito com que o Movimento Sindical de Trabalhadores Rurais, apesar do equilibrio que caracteriza a sua atuação, seja alvo da violência patronal e da repressão oficial. Violências contra trabalhadores e dirigentes sindicais tomaram-se fatos comuns no meio rural. Basta lembrar que somente em 1980 foram assassinados os líderes sindicais Raimundo Ferreira Lima, de Conceição do Araguaia (Pará) José Francisco dos Santos, de Correntes (Pernambuco) e Wilson Souza Pinheiro, de Brasiléia (Acre), por terem assumido a defesa dos trabalhadores. Ultimamente, no dia 18 de março de 1981, o trabalhador Edson Cardoso de Farias foi covardemente açoitado pelo seu ex-patrão, o 
médico e fazendeiro Adelson Henrique Paes por ter recorrido à Justiça de Campos (Rio de Janeiro) para receber o que tinha direito após 23 anos de trabalho.

No dia 27, de março em Santarém, no Pará, foram presos o líder sindical Ranulfo Pelaso da Silva e os trabalhadores Cristiano Freitas Rosas e Raimundo Croro (este, menor), porque apoiavam numerosas famílias de posseiros da Rurópolis Presidente Médice, que estāo aneaçados de despejo. Um dia depois, o companheiro José Pedro dos Santos, Presidente do Sindicato de Trabalhadores Rurais de Capela, em Alagoas, foi assassinado em frente à perta de sua casa, por um desconhecido que fugiu. José Pedro havia atrafdo contra si o ódio dos fazendeiros da regiāo, porquc denunciava, sempre, as irregularidades e desmandos contra os trabalhadores.

Ainda no dia 10 de maio, foi a vez do companheiro Marcelo dos Santos, delegado sindical na localidade de Cajazeiras, município de Codó (Maranhão). Ele foi brutalmente assassinado dentro de sua própria casa, com 7 tiros e nove facadas. Marcelo também apoiava a luta de mais de 400 familias da região, numa questão em que estão envolvidos nada menos que 4 grileiros.

Todas essas violências aconteceram num prazo inferior a dois meses. E todas elas constituem agressões ao legítimo exercício da atuação sindical. Todas elas foram praticacdas com o objetivo de impedir que os trabalhadores continuem se organizando para se defenderem contra a exploração e as injustiças de que sāo vitimas freqüentes. Todos foram vitimas fatais do braço armado a soldo da ganância ilimitada do interesse econômico, que já atingira o advogado Eugênio Lyra, em 1977, vitimara o advogado Agenor Martins de Carvalho em 1980, e, nesses últimos anos, tem assassinado dezenas de trabathadores rurais de todo o País, que lutaram para defender suas posses.

Cada vez que as forças anti-democráticas aumentam o seu espaço no quadro político, aumenta a repressão contra as entidades de trabalhadores. Assim foi em 1968, quando a CONTAG teve seu material impresso arbitrariamente apreendido e seus dirigentes obrigados a passar horas e horas depondo em organismos de segurança. Em 1973, foi o Ministério do Trabalho que quis impedir a realização do 2 . Congresso Nacional dos Trabalhadores Rurais. Em 1976, as denúncias patronais provocaram a apreensão de material didático da CONTAG no Acre, sendo seu presidente pessoalmente inquiridc pela Secretaria Geral do Conselho de Segurança Nacional. Em 1977, o Ministério do Trabalho suspendeu a posse da diretoria da CONTAG, 
e mais uma vez, a CONTAG foi ouvida pela Secretaria Geral do Conselho de Segurança Nacional sobre as publicaçōes do Movimento.

Agora, em plena 'abertura política", proclamada pelo Governo, mais uma vez os órgāos de segurança tentam atingir o Movimento Sindical de Trabalhadores Rurais. O pretexto é a morte do grileiro Nilo Sérgio Oliveira, praticada por um grupo de trabalhadores rurais inconformados com o assassinato do companheiro Wilson Souza Pinheiro, presidente do Sindicato dos Trabalhadores Rurais de Brasiléia. Pretendem as autoridades de segurança desconhecer que o problema fundiärio no Acre é grave e vem de muito tempo. Tanto que diante da intensificação dos conflitos e da tensão social na regiāo, - Movimento Sindical de Trabalhadores Rurais reivindicou a imediata desapropriação de 13 áreas de conflito.

Reconhecendo expressamente a existência de tensão social na regiáo, - Governo Federal, em setembro de 1980 decretou de interesse social, para fins de desapropriação, áreas no total de 262 mil hectares, nos municípios de Brasiléia, Xapuri e Rio Branco e que coincidiram com as áreas de conflitos, para as quais o Movimento Sindical reivindica a medida governamental.

Apesar de tudo. mais uma vez, sofrem os trabalhadores e suas entidades de classe pela falta de atuação do Governo no sentido de coibir esse estado de coisas. Contra os que assassinaram o Presidente do Sindicato nada de concreto foi feito. Alguns fazendeiros foram chamados para depor e não foi efetuada nenhuma prisão.

Contra os trabalhadores, armou-se um esquema de captura nunca visto. Foram torturados na prisão, tiveram que esperar quatro meses pela concessão de habeas corpus e aguardam julgamento pelo assassinato do grileiro.

Contra os dirigentes sindicais, a Polícia Federal, atendendo à solicitação da Federação da Agricultura do Estado do Acre, abriu inquérito policial militar e indiciou na Lei de Segurança Nacional membros da CONTAG, tendo sido o inquérito remetido à Justiça Militar, em Manaus.

Por se irmanar aos seus companheiros que lutavam pelos seus direitos: por promover a defesa desses direitos junto à Administração Pública e perante a Justiça; por protestar publicamente contra os assassinatos, violências e in. justiças de que têm sido vítimas os trabalhadores rurais brasileiros e seus líderes integrantes da CONTAG - incluindo o autor destas linhas - estão sendo processados na Lei de Segurança Nacional.

Entretanto, pode se assegurar que o Movimento Sindical, associado à luta de toda a classe trabalhadora. e com o apoio de pessoas, grupos, órgáos 
ou entidades comprometidos com a luta dos trabalhadores, não se afastará de seu compromisso com a organização, coordenação, estudo e defesa dos interesses da classe trabalhadora rural brasileira.

\section{CAMINHOS A SEGUIR}

A CONTAG congrega, hoje, 21 federações estaduais filiadas, 1 delegacia com atuaçāo no Acre/Rondônia e 2.447 sindicatos. Representa 11 milhões e meio de familias dentre as quais mais de 6 milhōes a 800 mil trabalhadores rurais sindicalizados, pequenos proprietários, arrendatários: parceiros, posseiros e assalariados.

0 interesse da categoria exige, primeiramente, uma reorientação do desenvolvimento e de toda a política agrícola e agrária, de modo a satisfazer as necessidades básicas e essenciais da maioria da populaçāo rural, como também urbana, através de uma estratégia de pleno emprego, distribuição de renda e ampliação do mercado interno.

No campo da política salarial, o Movimento Sindical iuta para intensificar a prática dos Contratos Coletivos de Trabalho, tanto lutando pela devolução do poder normativo da Justiça do Trabalho, quanto orientando e organizando suas bases para a celebração de dissídios, utilizando-se dos meios disponiveis, inclusive a greve, se necessário.

Já no campo sindical, a luta da CONTAG é no sentido de que sejam eliminadas as normas legais, expressas no Título $\mathrm{V}$ da Consolidação das Leis do Trabalho, que limitam ou impedem a organização dos trabalhadores e a conseqüente defesa de seus direitos, estabelecendo a autonomia e liberdade sindical.

Esse posicionamento implica também, na luta e participação dos trabalhadores rurais, juntando-se às lutas de outros segmentos da sociedade brasileira, pelo pleno restabelecimento das liberdades democráticas e do Estado de Direito, sem o que, qualquer modificação da Legislação Sindical, seria ineficaz.

A luta é também pela reformulação da política agrícola que, na prática, prejudica os trabalhadores, fortalecendo o latifúndio improdutivo. Os trabalhadores exigem uma política que garanta preços justos para seus produtos, acesso ao crédito, assistência técnica, facilidades na comercializaçăo dos produtos, etc... 
No campo da Previdência Social Rural muito se tem ainda que fazer. Trata-se de uma Previdência incipiente e com uma legislação discriminatória frente à Previdência Social Urbana. Lutam os trabalhadores rurais pela equiparação dos direitos e beneff́cios que já estão consagrados na Previdència Social Urbana, tais como: salário-fainflia, aux llio-doença, aposentadoria por tempo de serviço e assistência médico-hospitalar, entre outros.

Ditas alterações nos campos da Legislação Trabalhista e da política salarial, da política agrícola e da Previdēncia Social Rural são necessárias e urgentes, e por isso são objetivos da luta. Mas também é certeza do Movimento Sindical, que essas medidas serão ineficazes se não forem precedidas ou acompanhadas da transformação de nossa estrutura agrária, através da Reforma Agrária, ampla, imediata e com a participação dos trabalhadores rurais, isso porque:

a) Temos no Brasil mais de 11.400 .000 familias de trabalhadores rurais. No Nordeste, conforme estimativa do Banco Mundial, através de scu Centro de Pesquisa para o Desenvolvimento, pesquisa feita em 1977, são cerca de 6 milhões que fazem a força de trabalho do setor agricola, dos quais, mais da metade só encontra emprego durante 60 dias por ano. É, pois, uma mãode-obra desempregada ou subempregada.

b) Os minifúndios utilizam, no Brasil segundo dados de 1972 do INCRA, 48,5\% da força de trabalho no campo empregando uma pessoa para cada 7,7 ha. de terra explorada. Já o latifúndio por exploração emprega uma pessoa para cada 61,7 ha., existindo ainda o latifúndio por dimensāo, onde vamos encontrar o absurdo de uma pessoa para cada 9.600 ha.

c) O rendimento apresentado pelo minifúndio, de acordo com os mesmos dados, é 3,3 vezes superior ao obtido pelo latifúndio e é, também, superior à produtividade média do Paŕs. O rendimento, obtido pelos parceiros, chega a ser superior ao rendimento apresentado pelas empresas rurais.

d) Os minifundistas, parceiros e arrendatários juntos, participam com $20,5 \%$ da área total explorada e são responsáveis por quase $40 \%$ do valor total da produção agropecuária e extrativa no Brasil. No Nordeste, as menores unidades utilizam cerca de $60 \%$ de sua terra com culturas, enquanto que nas grandes propriedades essa percentagem vai caindo até chegar a $15 \%$.

e) Mas, segundo a pesquisa de 1977 do Banco Mundial antes mencionada, se todos os trabalhadores tivessem acesso à terra de forma a terem pleno emprego, uma simples extrapolação sugere que o produto poderia ser aumentado quatro vezes. Extrapolações dos parâmetros de função de produção in. 
dicam que o Produto Bruto poderia aumentar cinco vezes se a terra e o trabalho fossem combinados segundo uma condição de otimizaçāo".

Esses dados são suficientes para demonstrar que o latifúndio desperdiça terra, capital e trabalho, afetando a economia do País e trazendo reflexos sombrios para os trabalhadores rurais. Esses dados permitem, também, concluir que Reforma Agrária não é pulverização antieconômica da terra como muitos crèem, mas redistribuiçāo de renda de emprego, de poder e de direitos.

f) Não hả como insistir no argumento de falta de condiçōes e, pior ainda. falta de necessidade: há muita gente precisando de emprego produtivo na terra há terras suficientes, aproveitáveis, mas que se encontram inexploradas e retidas nas mãos dos latifundiários. Conta-se com instituiçōes para fazer a Reforma Agrária e dar assistência técnica; dispõe-se de instrumentação legal, representada pela Contituição Federal, o Estatuto da Terra, o Ato Institucional n: $9 \mathrm{e}$, ainda, Legislaçāo Complementar.

\section{A MODO DE CONCLUSÃO}

Diante da realidade dos trabalhadores rurais, diante da conjuntura social, econômica e politica do País, chega-se à convicção de que não é possivel haver solução duradoura para os problemas do Pais, deixando na marginalidade os trabalhadores rurais, que constituem quase $50 \%$ da população. Miesmo o projeto democrático fíca comprometido, a longo prazo, se não há uma verdadeira redistribuição da propriedade, da renda e do poder no meio rural, através de uma Reforma Agrária ampla, massiva, imediata e com a participação dos trabalhadores. Do mesmo modo que não se pode pensar, no mundo atual, em democracia verdadeira sem sindicatos atuantes, não se pode pensar em democracia, de fato, no Brasil sem que se integre a massa de assalariados, parceiros, arrendatários, posseiros e pequenos proprietários minifundistas, que constituem a classe de trabalhadores rurais, à vida sócioeconômica do País. Essa integração só se fará através da Reforma Agrária. Por isso, a Reforma Agrária é essencial. Por isso, a Reforma Agránia é a grande bandeira dos trabalhadores rurais. 